\title{
Introductory Lecture: Mechanochemistry, a versatile synthesis strategy for new materials
}

\author{
William Jones* and Mark D. Eddleston \\ Received 28th August 2014, Accepted 2nd September 2014 \\ DOI: $10.1039 /$ c4fd00162a
}

\begin{abstract}
Mechanochemistry deals with reactions induced by the input of mechanical energy - for example by impacts within a vibratory ball mill. The technique has a long history with significant contributions from Ostwald, Carey Lea and, notably, Faraday. Mechanochemistry has subsequently seen application in a variety of areas of materials science including mechanical alloying in metallurgy, the synthesis of complex organic molecules and, more recently, the discovery and development of new solid forms of active pharmaceutical ingredients. This paper overviews the broad areas of application of mechanochemistry, some key features which make it a particularly attractive approach to materials synthesis and some mechanistic aspects highlighted within the literature. A significant part, however, will focus on recent applications in the area of pharmaceuticals and its important role in exploring the rich variety of solid forms available for small, drug-like, molecules.
\end{abstract}

\section{Introduction}

Mechanochemistry is a long-established method for the synthesis of solids and molecules. Its chemical importance was recorded by Faraday, who in 1820 demonstrated the reduction of $\mathrm{AgCl}$ to $\mathrm{Ag}$ by grinding in a mortar and pestle a mixture of $\mathrm{AgCl}$ and $\mathrm{Zn} .{ }^{1}$ Significant progress followed, especially through the work of Carey Lea (1823-1897), ${ }^{2}$ and the position of mechanochemistry within the framework of chemistry as a whole was established by Ostwald who noted the equivalency of electrochemistry, thermochemistry, photochemistry and mechanochemistry..$^{3-5}$

Long held as an efficient process for the synthesis of metallic alloys, a recent extensive review by James et al. ${ }^{6}$ has highlighted several of the emergent areas now being actively pursued with regard to the application of mechanical energy in driving various transformations - indeed a working definition from that review is "mechanochemistry refers to reactions, normally of solids, induced by the impact of mechanical energy such as grinding in ball mills". A formal definition by IUPAC states "a mechano-chemical reaction is a chemical reaction that is induced by 
mechanical energy".7 Although a narrow definition of mechanochemistry may lead to a suggestion that the making and breaking of covalent bonds would be a prerequisite for a process to fall under the definition of "mechanochemistry", following the appreciation of the importance of "non-covalent bonds" in supramolecular chemistry it seems reasonable to include changes in crystal packing to be a mechanochemical event. Links to mechanochemical activation by ultrasound have also been proposed., ${ }^{\mathbf{9} 10}$

This paper will briefly summarise recent developments in mechanochemistry, particularly in its application in pharmaceutical materials science and its role in the development of new solid drug dosage forms, to complement earlier literature which has covered extensively metals and alloys and inorganic (ionic) systems. As we will describe later, the amount of energy which can be imparted to a system under mechanical activation can be significant - certainly sufficient to break chemical bonds ${ }^{6}$ - but can also be reduced when working with systems such as soft molecular crystals in order to minimise chemical activation while still enabling processes such as the conversion of a crystalline solid to an amorphous product, ${ }^{\mathbf{1 1}}$ or the readjustment of molecules within a lattice. Such readjustments may lead to the introduction of lattice imperfections, ${ }^{12}$ to polymorphic transformations ${ }^{13}$ or to the intimate mixing of two separate crystalline molecular solids to create a crystalline multicomponent product indistinct from that which would be obtained by a conventional solution crystallisation. ${ }^{\mathbf{1 4}}$ Particularly advantageous in mechanochemical transformations is the avoidance of the need for large volumes of solvent (as required, for example, in the recrystallization of poorly soluble molecules), and hence a strong "Green Chemistry" aspect to mechanochemistry is recognised..$^{15,16}$ In terms of commercial interest, the review by James et al. describes a search of patent applications for the terms "mechanochemical" and "mechanochemistry" which revealed a significant increase in usage in the patent literature from 1980 onwards. ${ }^{6}$

\section{Areas of application and development}

The areas in which mechanochemistry has been applied with success are varied and include: catalysts, ${ }^{17}$ nanoparticles ${ }^{18-20}$ organic synthesis,${ }^{21-27}$ MOFs, ${ }^{28}$ oxides ${ }^{29}$ biomaterials, ${ }^{30,31}$ supramolecular chemistry, ${ }^{32-34}$ process engineering,${ }^{35}$ dyes and pigments, ${ }^{36}$ fluorophores, ${ }^{37}$ exfoliation of graphene nanosheets ${ }^{38}$ and modification of fullerenes (see Fig. 1). ${ }^{39}$ Numerous further examples are given in the review by James et $a .^{6}$ and several other reviews on the application of mechanochemistry are available..$^{28,40-47}$ In particular, the contributions of V. V. Boldyrev and his colleagues to both experimental and theoretical aspects of mechanochemistry have been important to the subject. ${ }^{\mathbf{3 , 9 , 4 8 , 4 9}}$

From a synthetic chemistry viewpoint an important observation is that substances can react by a significantly different pathway in the solid state than they would in solution, leading to new products or to much higher selectivities. ${ }^{50,51}$ This ability to generate a much broader product-spectrum, as we will demonstrate later, is also particularly important in areas other than chemical transformations e.g. in crystal polymorph conversions - and it is to be noted that the addition of very small amounts of liquid may have a significant impact on the outcome of a solid-solid reaction, even though quantities are much less than a conventional solvent-based reaction might require - see later. 


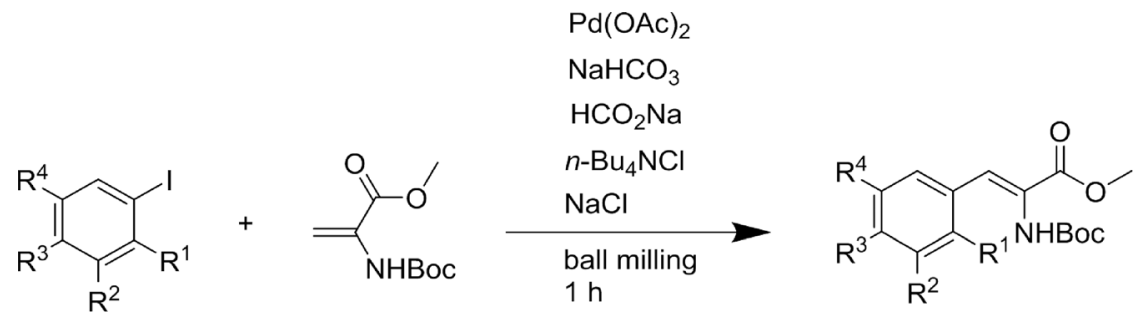

Fig. 1 General scheme for the Heck reaction under ball milling conditions. Reproduced from ref. 6.

A key area of active research remains the understanding of the processes by which mechanically induced reactions occur. ${ }^{52}$ Given the variety of materials of interest, ranging from metals and ceramics to pharmaceuticals, the specific details of how a process occurs will likely be varied and complex. ${ }^{3,53,54}$ Also to be distinguished is the time-scale over which an event is studied. During the few milliseconds following the impact of two solids at high velocity, significant local consequences will ensue. Hot spots, magma-plasma regions, rapid induction of defects (point, linear and planar) and then propagation of these defects through the crystal are some of the concepts which have evolved. The distribution of imparted energy will also be different in those solids with high rigidity and few pathways for energy dissipation (so that the effects at the specific point of impact will be great) than it is in those systems where structural movement (e.g. slippage of crystal planes) may allow the energy (and its consequences) to be distributed over a much larger distance. ${ }^{3}$ During this early stage, the making and breaking of chemical bonds would seem possible. Following the initial short-term consequences, there will also be the longer term events associated with the final energy dissipation and relaxation of the system. The slow crystallisation of an intermediate amorphous phase may be such an example (see Fig. 2 and 3). ${ }^{\mathbf{1 1 5 2 , 5 5 , 5 6}}$ It is possible, then, to envisage that an individual particle, for example within a milled pharmaceutical material, may be completely amorphous initially, but over time
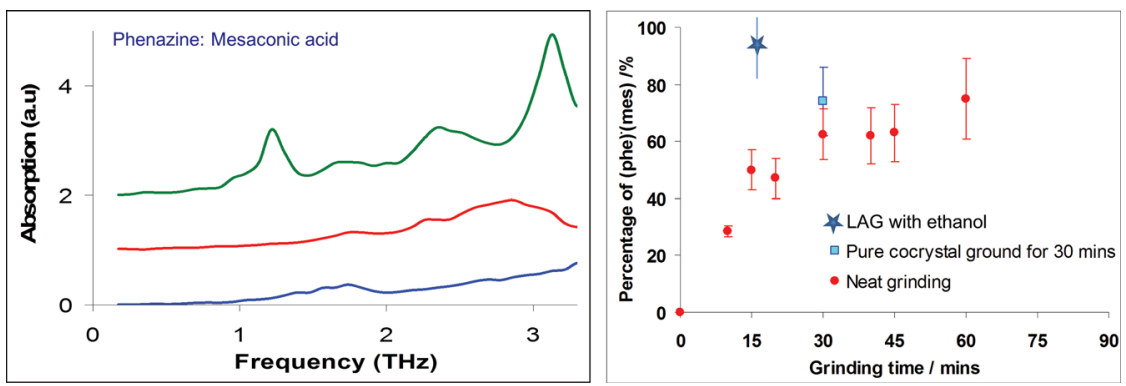

Fig. 2 (a) Terahertz spectra obtained from (top to bottom): a 1:1 mesaconic acidphenazine cocrystal; mesaconic acid; phenazine. (b) Analysis (ex situ) of the extent of formation of the cocrystal from a mixture of phenazine and mesaconic acid, as a function of neat grinding time, as measured using the characteristic cocrystal band at $1.1 \mathrm{THz}$ (red circles). The blue star, by comparison, shows close to $100 \%$ conversion in 15 minutes as a result of the presence of liquid in a LAG experiment. The blue square represents the percentage of a cocrystal sample that remained crystalline during dry grinding. ${ }^{56}$ 
may change to consist of domains of crystalline solid embedded within an amorphous shell (or more likely vice versa where, for example, humidity from the surrounding atmosphere results in each amorphous particle crystallising from the outside). This model might suggest that a description of a product as $25 \%$ amorphous does not mean that $25 \%$ of all the particles are amorphous and $75 \%$ are not - but that each individual particle within the product consists of domains of crystalline and amorphous in a $3: 1$ ratio.

A key factor for potential commercial exploitation in many instances would seem to be difficulties associated with scale-up. The progression from gram-scale, lab-based synthesis to kilogram-scale or higher outputs is an issue that has been addressed in many industrial applications ${ }^{3}$ and more recently in the area of pharmaceuticals, where twin extrusion approaches are employed (Fig. 4). ${ }^{57,58}$ Furthermore, it is noteworthy that frequently the generation of a new material (e.g. in the case of molecular crystals) at the gram level can allow, through subsequent seeding of a supersaturated solution, production via a conventional solvent-based crystallisation route. ${ }^{59}$

It is also necessary to recognise the need for methods of structurally characterising the products of mechanochemical processes. When applied to chemical conversions which may occur, molecular identity can be established by conventional analytical methods (e.g. solution NMR and mass spectrometry). For solidsolid transformations, where the identity of crystalline intermediates or final states is required, major improvements in crystal structure determination from powder Xray diffraction data (frequently coupled with solid-state NMR) have been pivotal. ${ }^{60-64}$ In addition, the structural analysis of individual crystallites that result from mechanochemical processes is possible through utilisation of the electron diffraction facility of the transmission electron microscope. ${ }^{65-67}$
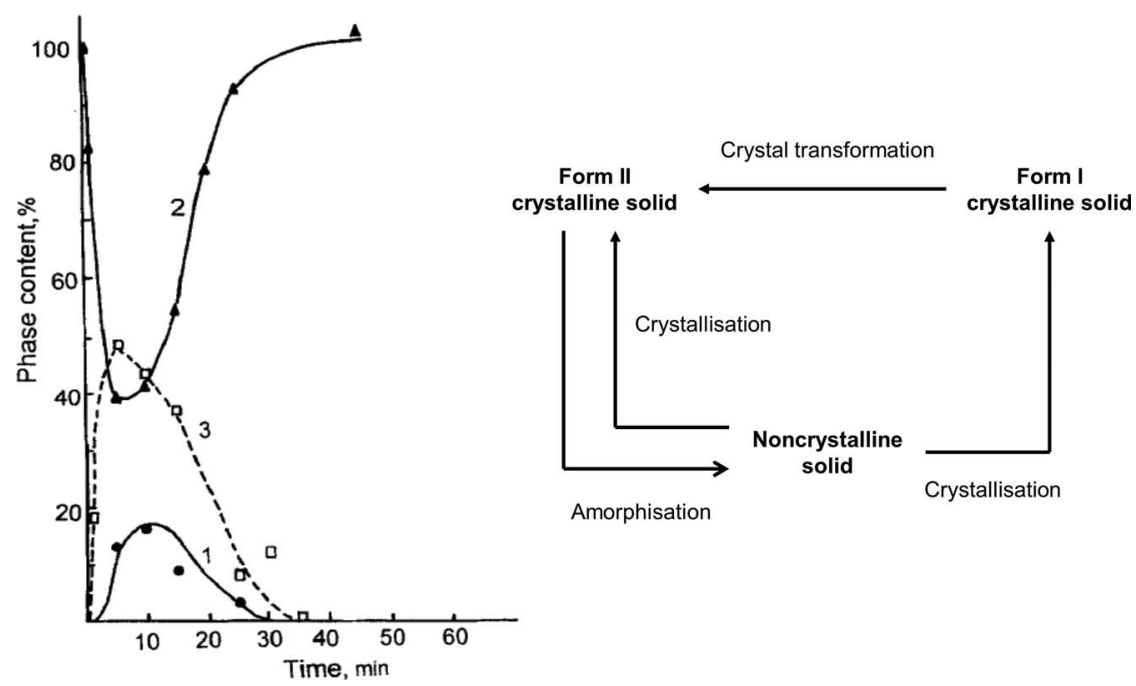

Fig. 3 (a) Schematic of the different pathways occurring during the mechanochemical treatment of sulphathiaziole. Mechanical treatment resulted in the partial amorphisation of the drug and the interconversion of Forms I and II. (b) Time profile for the phase interconversion for sulphathiazole: 1 - indicating generation of Form l; 2 - initial loss and subsequent regeneration of Form III; 3 - the existence of a transient amorphous phase. Figure adapted from ref. 55. 


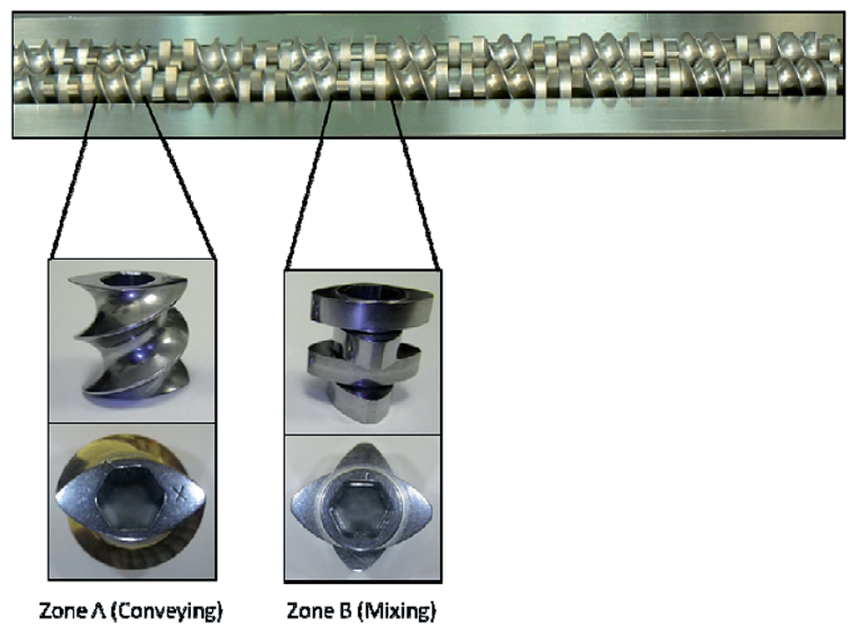

Fig. 4 Typical twin extrusion configuration used for the formation of cocrystals. The conveying and mixing zones are shown. Typical output rate is approximately $0.5 \mathrm{~g} \mathrm{~min}^{-1}$. PXRD suggests comparable properties for the product to that obtained by conventional solution growth. The possibility of simultaneously blending the cocrystal product within a polymer matrix is an important additional advantage of the method. Reproduced from ref. 58.

\section{Pharmaceutical materials}

Within various areas of process engineering (including food science, chemicals and pharmaceuticals) particle size reduction is an important step. ${ }^{35,68}$ Approaches to size reduction include compression (e.g. rollers) or impact (e.g. impact mills and ball mills). All methods involve transfer of varying amounts of energy to the

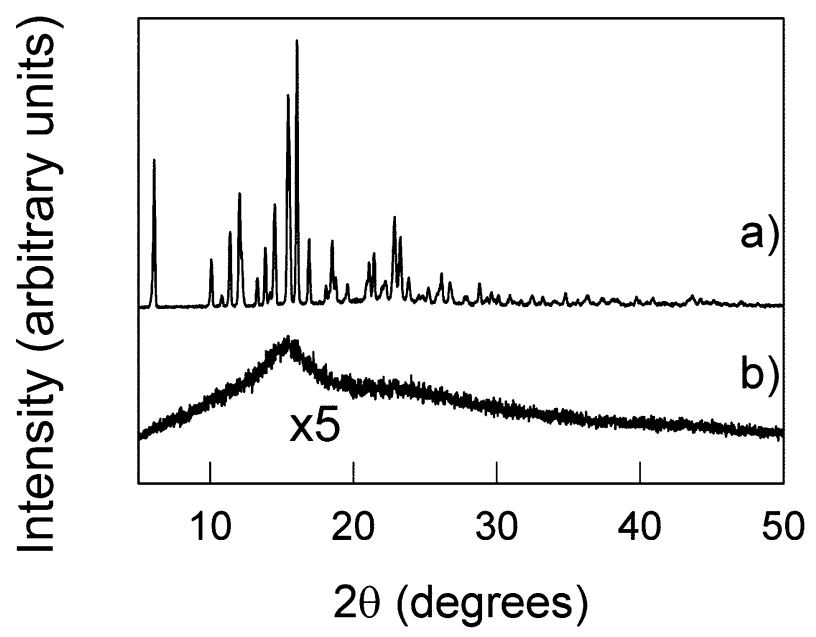

Fig. 5 Demonstration of the amorphisation of trehelose as a result of milling at room temperature within a high energy planetary micro-mill. PXRD patterns (a) before and (b) after milling. Adapted from ref. 11. 

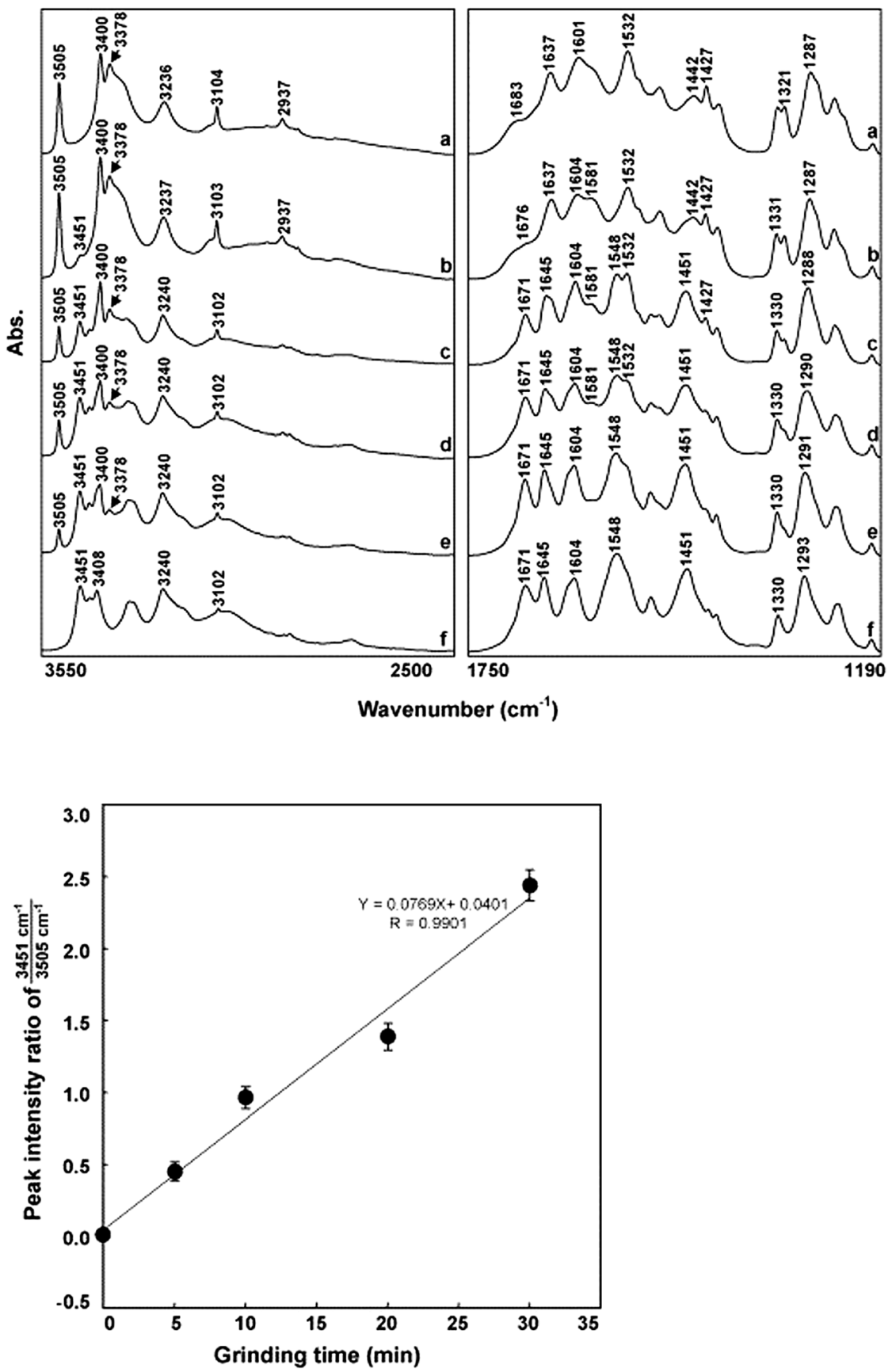

Fig. 6 (a) Grinding-time dependence of the FTIR spectra for famotidine showing from top to bottom the emergence of the absorption at $3451 \mathrm{~cm}^{-1}$ which is used to monitor the formation of Form $A$ of the material. (b) Plot of peak intensity ratio $\left(/ / 3451 / /_{3505}\right)$ for the spectra above indicating a possible zero order rate law for the conversion. Reproduced from ref. 78 with permission from Elsevier. 
particle(s), and as a result other consequences can accompany the size reduction including the introduction of defects (such as dislocations, point defects and stacking faults) $)^{12}$ and in particular amorphisation $^{69}$ or polymorphic transformations. ${ }^{70}$

The work of Descamps and others with regard to pharmaceutical materials has clearly demonstrated the critical role of the glass transition temperature, $T_{\mathrm{g}}$, in determining whether or not a persistent amorphous phase will be generated..$^{11,71-73}$ The combination of increased milling intensity and the absence of any plasticisers, which might lower $T_{\mathrm{g}}$ (either as liquid or vapour, e.g. water, from the surrounding atmosphere), will encourage the formation of an amorphous product (Fig. 5). The distinction between amorphous and crystalline products is particularly important for pharmaceutical applications given the inherent increased transient solubility (and hence improved bioavailability) associated with amorphous compared to crystalline solid forms. ${ }^{69,74-76}$

Frequently, the amorphisation of a material can be a desirable outcome, especially as a means of increasing the transient solubility of the material or of eliminating compression issues with the crystalline equivalent. ${ }^{68}$ This attribute is frequently used in the pharmaceutical industry, and the complex nature of the resulting solids has been extensively studied (especially with regard to the instability of the amorphous form with respect to the crystalline state). ${ }^{74}$

Polymorphic transformations from the stable to a metastable form (again with increased apparent solubility) can also be a useful consequence of the application of mechanical energy (Fig. 6). ${ }^{13,77-79}$ Jet-milling, a particle-size reduction method frequently used within the pharmaceutical industry where particle-particle collisions occur within a carrier gas (typically air), has, for example, been found to induce polymorph interconversions along with the size reductions.

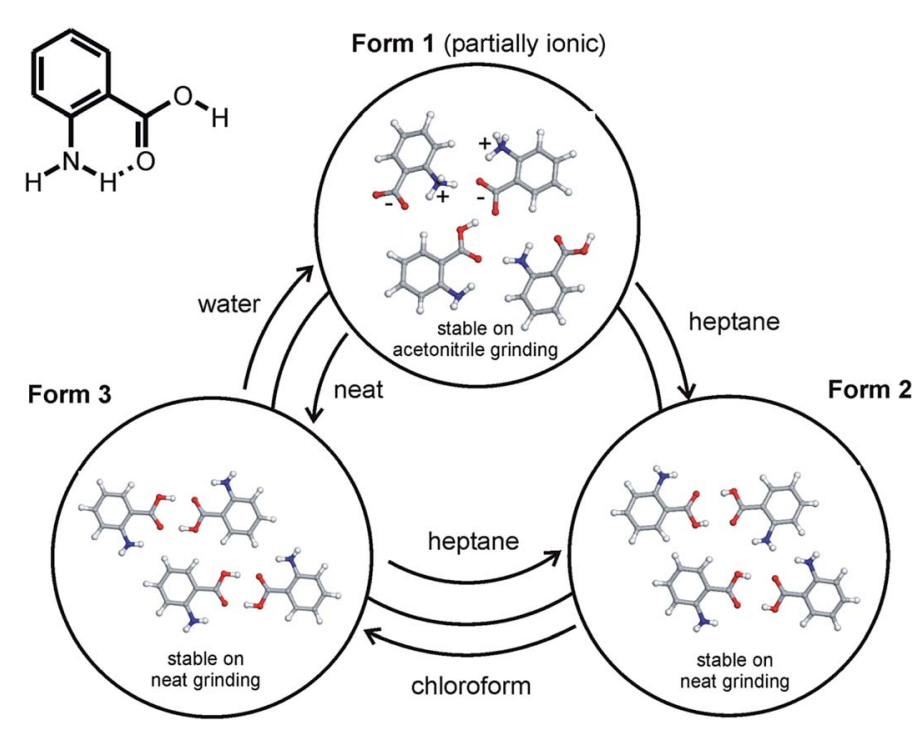

Fig. 7 Schematic of the observed transformations between the three polymorphic forms of anthranilic acid with the pathways depending on the conditions under which mechanochemical treatment was performed. 
With grinding experiments, an approach for directing the polymorphic outcome through addition of a small amount of liquid was described by Trask et al. for the cases of anthranilic acid and succinic acid (see Fig. 7). ${ }^{80}$ For anthranilic acid, interconversion between the three known polymorphic forms occurred depending upon the choice of the added liquid. ${ }^{81}$ In the case of succinic acid, while the $\beta$-polymorph appeared stable to neat grinding, addition of a few drops of a low polarity liquid (e.g. hexane) caused conversion to the $\alpha$-polymorph. More polar liquids (e.g. water, acetonitrile or methanol) appeared not to induce the transformation. The actual mechanism of the solid-solid transformation is an area of ongoing interest, especially where the change appears to be crystal-crystal in nature. ${ }^{82}$

An additional reason for interest in mechanochemical processes comes from the fact that the majority of drugs (80-90\%) are formulated as tablets, which are seen as a reliable and general way of delivering medicines, and that the tableting process itself requires the application of significant applied pressures (see Fig. 8). ${ }^{55,83-90}$ Importantly, tablets contain other components (excipients), which are added to enhance performance e.g. lubricants, dissolving agents and so on. When pressure is applied during compression, there is a risk that surface-surface reactions between the components and drug, such as that between dicalcium phosphate dihydrate and aspirin, will lead to enhanced instability. ${ }^{91}$

More recent interest has focused on the formation of cocrystals (see Fig. 9) by milling or grinding. ${ }^{92-94}$ One of the earliest examples of a cocrystal obtained by grinding is that of quinhydrone reported in the work of Wohler published in 1844..$^{95}$ The advantage for this system compared to solution crystallization was shown by Patil et al., ${ }^{96}$ who demonstrated that simple grinding of mixtures was significantly superior to attempted solution growth, where self oxidation-reduction lowered the efficiency of complex formation. Subsequently, numerous examples of host-complex formation by solid-solid mixing were reported by Toda and co-workers. ${ }^{50}$ Work by Etter and colleagues also demonstrated how solidsolid grinding could be used to produce hydrogen bonded cocrystals of adenine and thymine derivatives, where a marked selectivity amongst various base pairs was observed. ${ }^{14}$ Hollingsworth et al. ${ }^{51}$ used grinding as a means of creating cocrystals of dinitriles and urea, as part of a wide study of inclusion crystals, in cases where solution growth was not possible. Pedireddi et al. demonstrated that in
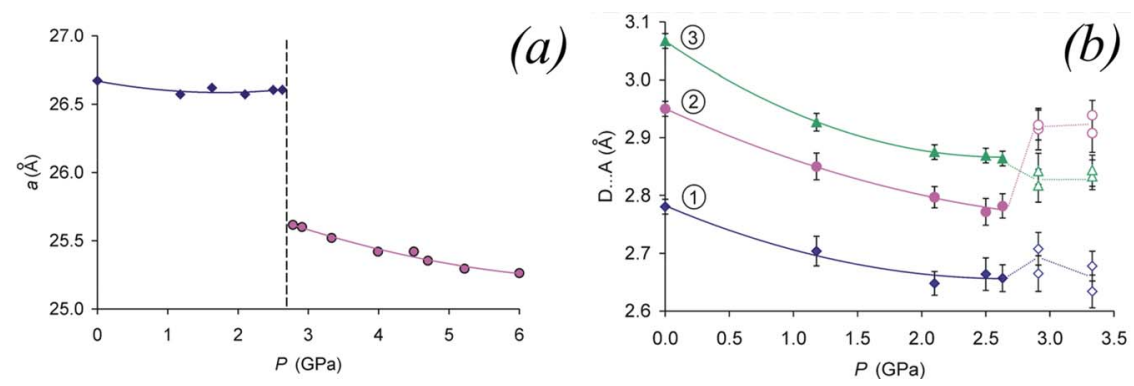

Fig. 8 (a) Hydrostatic pressure induced transition for chlorpropamide in a saturated ethanol solution. The phase change results in a first order change at approximately 3.5 GPa. The change is illustrated for the a-axis. (b) Changes in non-hydrogen atom positions as the transition pressure is reached. Adapted from ref. 46. 

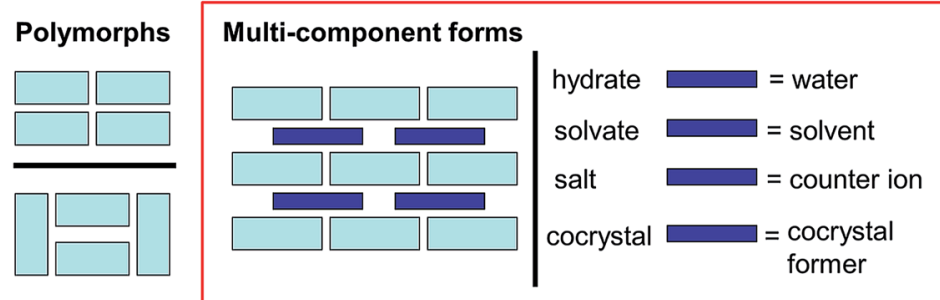

Fig. 9 Schematic of the characteristics of polymorphs and multicomponent systems. Cocrystals represent a sub-set of the multicomponent group, frequently that characterised by the requirement that the components be neutral and solid at room temperature.

some cases a third component is necessary in order for a cocrystallisation reaction to take place ${ }^{97}$ and Kuroda and her colleagues studied the influence of the addition of a third component on the optical properties of the resulting cocrystals. ${ }^{98}$

Frequently, the solid state properties of a pure drug can present processing or application problems e.g. particle flow, thermal stability, stability to moisture or ability to be compacted, ${ }^{68}$ and, increasingly, poor solubility is an issue. ${ }^{99,100}$ The challenge with a badly behaving drug, therefore, is to be able to control the properties of the molecule in the solid state without recourse to chemical modification by covalent chemistry. The use of multicomponent systems, especially pharmaceutical cocrystals, and more recently ionic cocrystals, ${ }^{\mathbf{1 0 1}, \mathbf{1 0 2}}$ has been demonstrated to be an effective strategy in such instances. ${ }^{103-112}$ In terms of property improvement with pharmaceutical cocrystals, various examples are known including: enhancing stability against hydration of an anhydrate form (see<smiles>Cn1c(=O)c2c(ncn2C)n(C)c1=O</smiles><smiles>O=C(O)C(=O)O</smiles><smiles>O=C(O)CC(=O)O</smiles><smiles>O=C(O)CCC(=O)O</smiles><smiles>O=C(O)CCCC(=O)O</smiles>

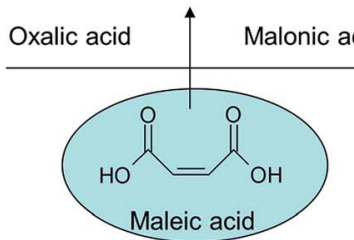

Succinic acid Glutaric acid<smiles></smiles>

Fig. 10 Supramolecular synthon approach used in the design of cocrystals of caffeine with various dicarboxylic acids. This approach lead to a variety of solid forms of caffeine which could be tested for stability under conditions of high humidity. Mechanochemistry was the technique used to both screen for cocrystal formation and also prepare powders for humidity assessment. 


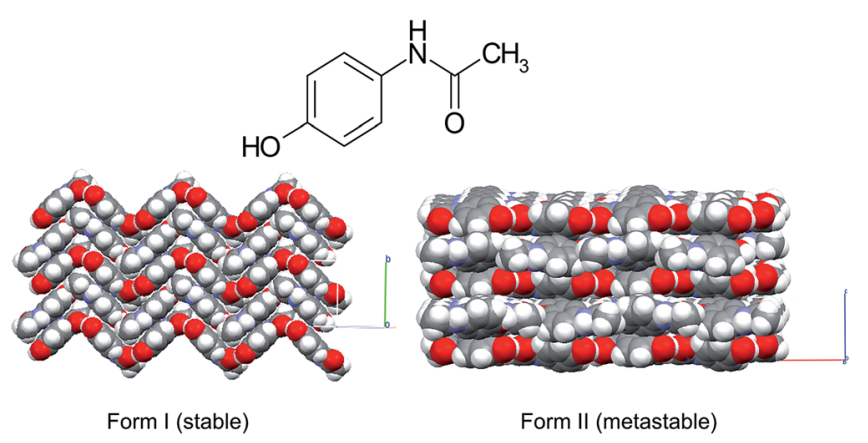

Fig. 11 Packing diagrams for Form I and Form II paracetamol. Whilst Form I is the stable phase it does not compress well during tablet formation. The metastable Form II has a layered structure more appropriate for compression, but readily transforms to Form I.

Fig. 10), ${ }^{113-116}$ developing forms with improved compression properties (for tablet formation) (see Fig. 11 and 12), ${ }^{\mathbf{1 1 7}, \mathbf{1 1 8}}$ significantly improving the bioavailability of poorly soluble drugs and controlled release strategies e.g. for insulin. ${ }^{119}$ Trask has reported on the potential intellectual property implications of pharmaceutical cocrystals, ${ }^{120}$ and recent interest has also focused on regulatory guidelines. ${ }^{121}$ In non-pharmaceutical applications, benefits of cocrystallisation have been shown for fluorescent materials ${ }^{37,122}$ and explosives. ${ }^{123,124}$

An early indication of the potential to form pharmaceutical cocrystals by grinding was provided by Caira et al. in 1995 who used grinding to prepare a series of crystalline products containing sulfonamide (similar to those obtained from solution) in a facile manner. ${ }^{125}$ They also reported detailed solid state kinetic data based on powder X-ray measurements and were able to show a distinct selectivity between reactants during grinding.

An ongoing challenge, however, is selecting possible coformers which might cocrystallise with the API rather than remain as a separate and distinct crystalline phase. Whilst various strategies have been developed to predict the likelihood of cocrystal formation, ${ }^{\mathbf{1 2 6 - 1 2 9}}$ experimental screening for viable coformers remains vital (Fig. 13). ${ }^{\mathbf{1 3 0 - 1 3 2}}$ While solution growth remains the ideal approach - especially with regard to scale-up in later stages of development - significant differences in solubility between the drug and coformer often presents difficulties. ${ }^{115,116,133-135}$ Mechanochemistry has emerged as a powerful tool in the experimental screening area, and has the advantage of minimising the need for large volumes of solvent (Fig. 14). It has also emerged as a powerful way of searching for different

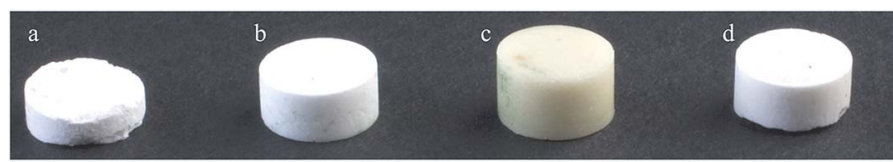

Fig. 12 Micrographs of tablets made from (a) paracetamol Form I and ( $b$ to d) cocrystals of paracetamol with theophylline, naphthalene and oxalic acid respectively. Tablet (a) is poorly formed as a result of the inappropriate packing of the molecules in the lattice, whereas the cocrystal structures are amenable to deformation during tableting ${ }^{118}$ 
polymorphic forms of cocrystals ${ }^{135,136}$ as well as for various stoichiometric compositions e.g. $1: 1,1: 2$ and $2: 1 .^{59}$ Furthermore, mechanochemistry has been used to identify chiral agents suitable for converting a racemate into two distinct diastereomeric cocrystal phases ${ }^{137}$ as well as for coformer exchange. ${ }^{138}$

An extension to simple (i.e. neat or dry) grinding of mixtures was reported by Shan et al. who added a few drops of liquid to the reaction mixture (liquid assisted grinding, LAG) (see Fig. 15). ${ }^{139}$ Initial attention focused on LAG as a means of accelerating cocrystallisation kinetics, although it was subsequently shown to provide a means of increasing product diversity. For example, the outcome of mechanochemical formation of cocrystals has been compared with that from using other approaches to cocrystallsation. Trask et al. reported three possible
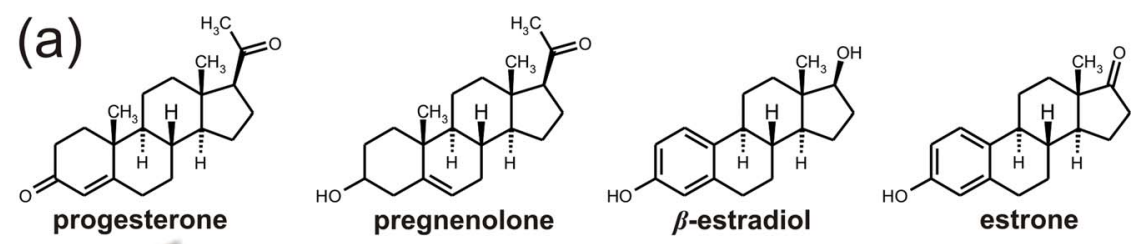

increase in cocrystallisation propensity towards arenes

(b)<smiles>O=C(O)c1ccc2ccccc2c1</smiles><smiles>Oc1cc(O)cc(O)c1</smiles><smiles>Oc1cccc2ccccc12</smiles><smiles>Oc1ccc2ccccc2c1</smiles><smiles>O=C(O)c1c(O)ccc2ccccc12</smiles><smiles>O=C(O)c1ccc2ccccc2c1O</smiles><smiles>OC1CCC2CCCCC2C1</smiles><smiles>Oc1ccc2ccc3cccc4ccc1c2c34</smiles><smiles>Oc1cc2ccccc2c2ccccc12</smiles><smiles>O=C(O)c1cc(Oc2ccc3ccc(O)cc3c2)ccc1O</smiles><smiles>Cn1c(=O)c2[nH]cnc2n(C)c1=O</smiles><smiles>Cn1cnc2c1c(=O)[nH]c(=O)n2C</smiles><smiles>c1ccc2ccccc2c1</smiles><smiles>Fc1c(F)c(F)c2c(F)c(F)c(F)c(F)c2c1F</smiles>
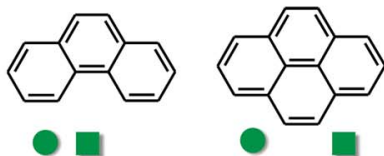

= forms a cocrystal with progesterone

$=$ does not form a cocrystal with progesterone

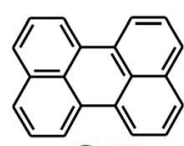

0

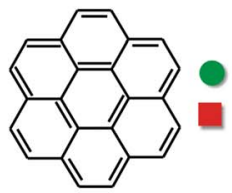

$=$ forms a cocrystal with $\beta$-estradiol

$=$ does not form a cocrystal with $\beta$-estradiol

Fig. 13 The use of mechanochemistry to explore the various possible combinations of coformers for a family of steroid drugs. The various outcomes are delineated by the accompanying legend. See ref. 161 for details. 
outcomes in the case of cocrystals with caffeine: (i) solution growth and milling produced identical products; (ii) a different stoichiometric product could be obtained by milling compared to solution; and (iii) different polymorphic forms were possible. ${ }^{59}$ Numerous recent publications have demonstrated that LAG is likely to be the most efficient way of screening for cocrystal formation. ${ }^{\mathbf{1 4 0 - 1 4 4}}$ The key advantage of LAG over solution based approaches was interpreted by Davey, ${ }^{145,146}$ Childs $^{\mathbf{1 4 7}}$ and others ${ }^{\mathbf{1 4 8}}$ on the basis of solution phase chemistry (Fig. 16). Other developments, such as ion- and liquid-assisted grinding (ILAG) ${ }^{\mathbf{1 4 9}}$ and vapour digestion of solid mixtures, ${ }^{150,151}$ have also been reported.

Further insight has been given by the recent work of Bučar et al. for the case of caffeine and benzoic acid. ${ }^{152}$ No cocrystals for this pair of molecules were known despite a strong expectation based on studies of analogous systems ${ }^{153}$ and despite extensive experimental efforts to generate such a species over many years. A systematic study using a large range of cocrystallisation methods including neat grinding, liquid assisted grinding, melt crystallization and various solution methods was employed (Fig. 17). All failed to produce the elusive cocrystal even though theoretical work had clearly confirmed a cocrystal was thermodynamically feasible. During grinding experiments, however, the addition of a few seed crystals of an isostructural fluorobenzoic acid cocrystal readily generated the elusive cocrystal, with the inference being that, as in solution crystallisation, a high barrier to nucleation of a particular form can frequently exist.

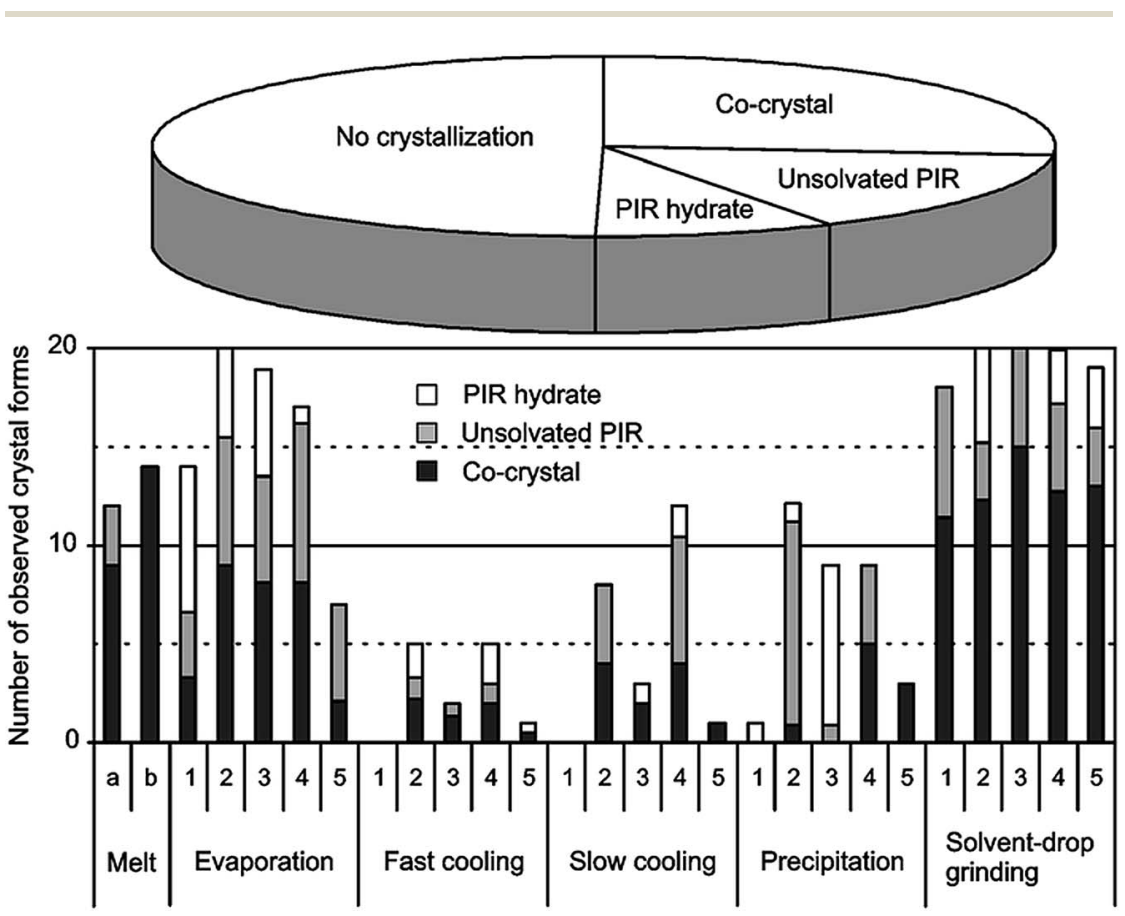

Fig. 14 Overview of the results obtained by various cocrystallisation attempts for piroxicam. Solvent-drop grinding (LAG) is shown in this case to be the most efficient and straightforward screening method. The numbers 1-5 indicate the various solvents used in the experiments. Reproduced with permission from ref. 142. 


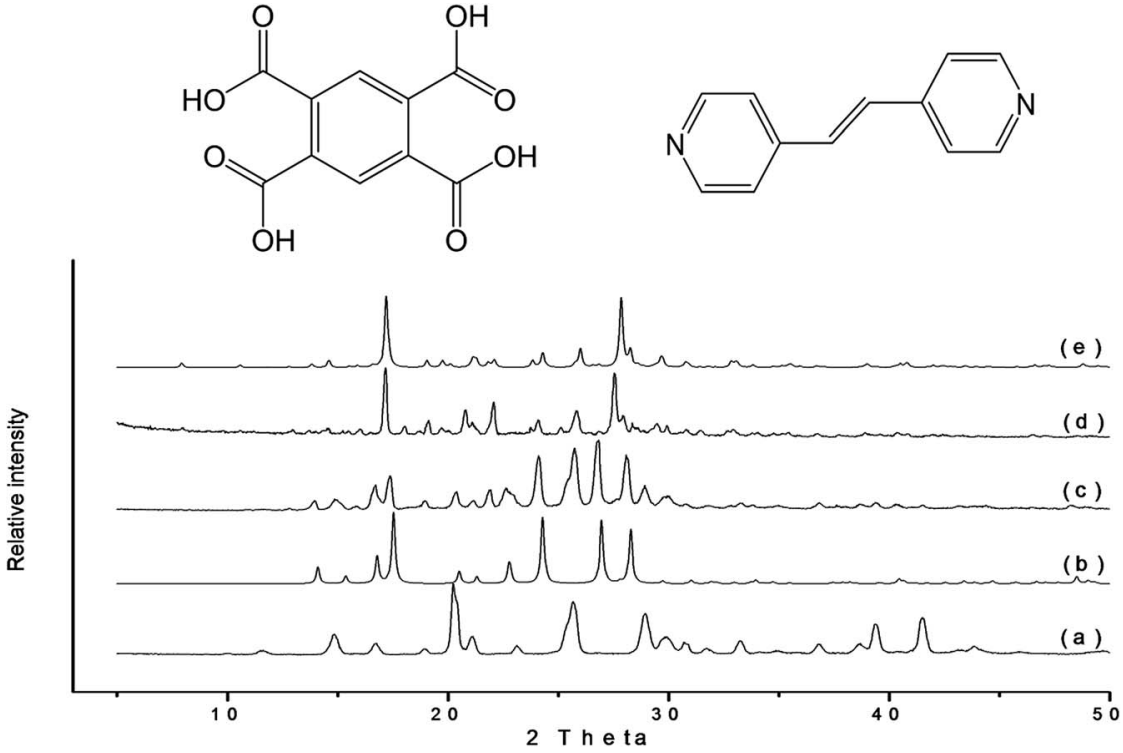

Fig. 15 Demonstration of the enhanced kinetics of cocrystal formation upon addition of a few drops of methanol to the grinding jar. PXRD patterns for (a) tetracarboxylic acid, (b) bipyridyl, (c) outcome of neat grinding for 60 minutes (as the sum of the reactants), (d) the product obtained when a few drops of methanol are added and (e) the simulated pattern for the cocrystal.

Accompanying the recent developments in mechanochemistry has been the development of techniques to follow the course of solid-solid reactions using both ex situ and in situ approaches. ${ }^{56,122,154-158}$ Ex situ analysis has frequently suggested that there may be distinct intermediates generated (Fig. 18). ${ }^{154,159}$ The application of synchrotron X-ray diffraction for in situ studies has indeed confirmed the presence of crystalline intermediates and a possible role of amorphous phases. ${ }^{157}$ To better understand the processes occurring during
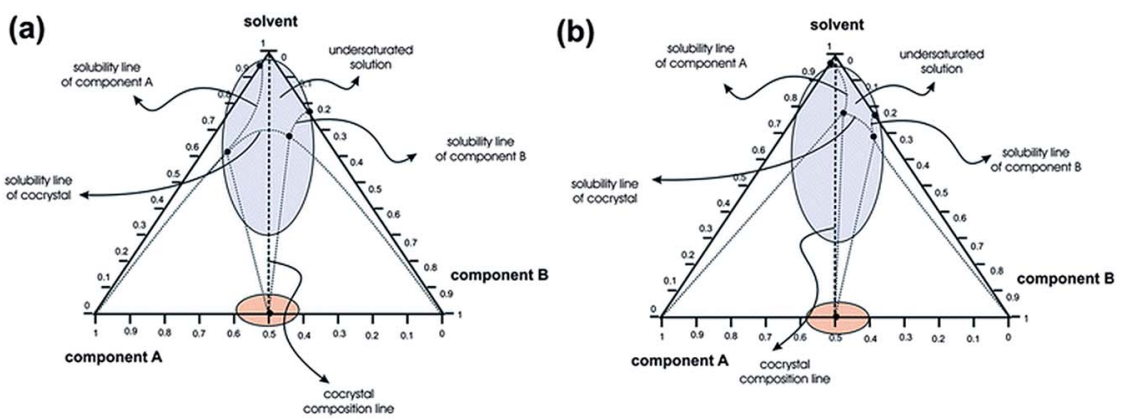

Fig. 16 Typical three-component phase diagrams contrasting (a) congruent and (b) incongruent solubility profiles indicating the difficulties which will arise during conventional evaporative solution growth crystallisation. The fact that LAG experiments, with minimal amounts of solvent present, places the system close to the cocrystal composition illustrates the ability of LAG to form cocrystals when solids of very different solubility are investigated. Reproduced from ref. 34. 


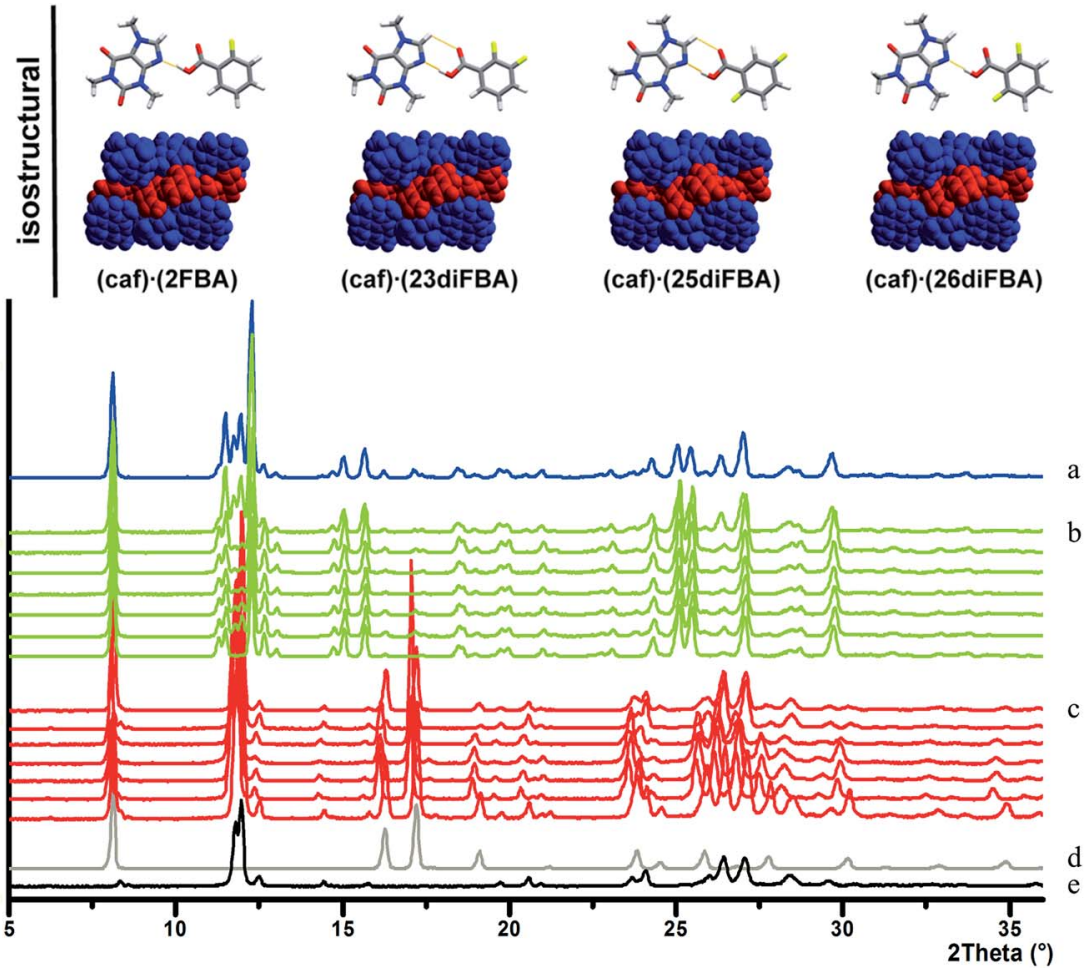

Fig. 17 Top. Isostructural cocrystals of caffeine with various fluorobenzoic acids which have similar packing to that predicted for the likely structure of the caffeine-benzoic acid cocrystal. Bottom. PXRD traces of (a) product without deliberate addition of seeds, but prepared in an environment where the caffeine-benzoic acid cocrystal had previously been obtained, (b) products of various seeding reactions, (c) products of various unseeded reactions, (d) benzoic acid and (e) caffeine. The main points to note include the similarity of the patterns in (a) and (b) and that those in (c) are a simple combination of the starting materials in (d) and (e). See ref. 152 for more details.
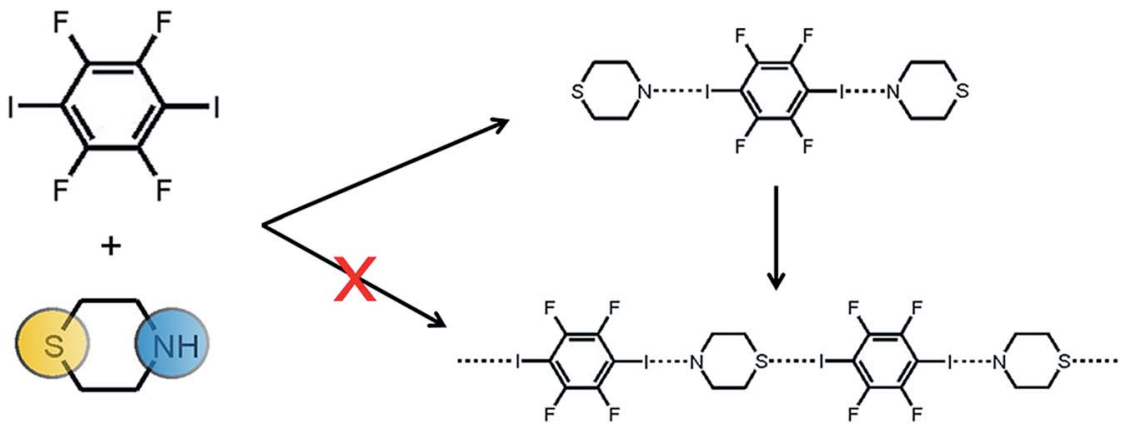

Fig. 18 The discrete trimer units and extended polymer chains (based on halogen bond interactions) believed to be formed during the LAG reaction. When the strength of the halogen bond is weak the product is limited to the trimer unit. 

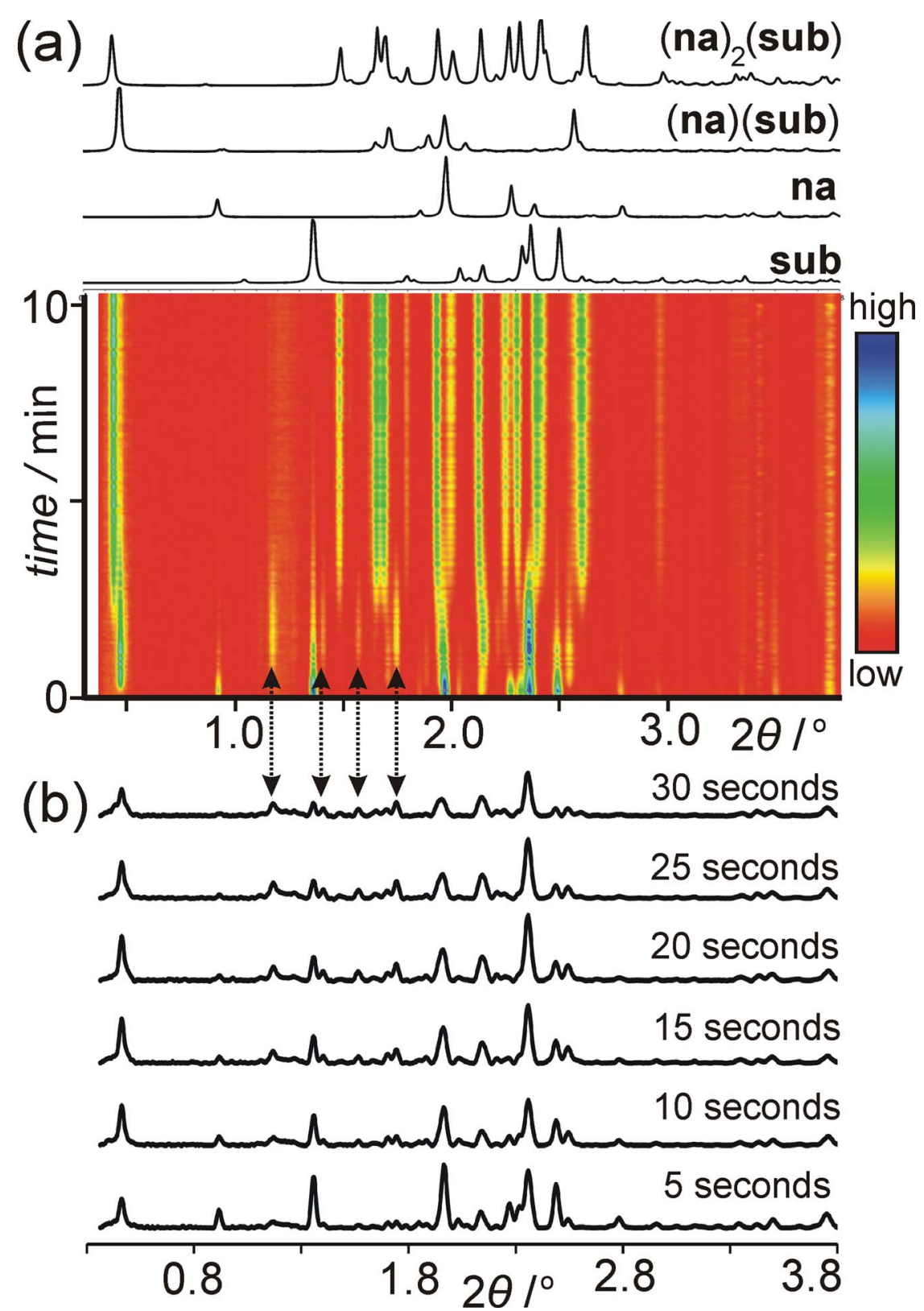

Fig. 19 In situ synchrotron data for the milling of suberic acid and nicotinamide in a $2: 1$ ratio. (a) The PXRD patterns of the phases expected to be formed during milling along with the data obtained as a function of time. The inset shows the particular region at 0.4 to 0.5 degrees two-theta showing the initial formation of the $1: 1$ cocrystal followed by the $2: 1$ product. (b) The specific reflections indicated by arrows indicate the intermediate phase which is not detected by conventional ex situ studies. See ref. 157 for further details.

milling, several recent efforts have concerned developing methods to follow in situ the course of the reaction. Noteworthy has been the use of synchrotron X-ray diffraction. In a study of the milling of a mixture of carbamazepine and succinic 

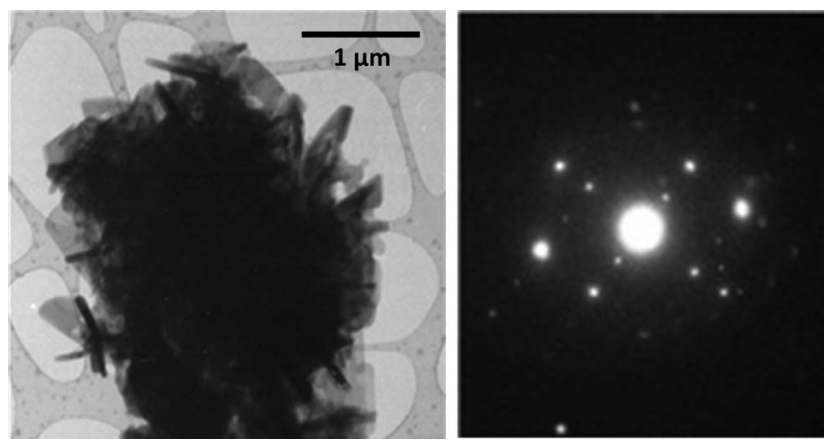

Fig. 20 (a) Transmission electron micrograph and (b) electron diffraction pattern obtained from a sample of a theophylline:L-malic acid cocrystal prepared by LAG. The method is able to monitor particle size as well as polymorphic form. ${ }^{160}$

acid, Halasz et al. ${ }^{157}$ showed that, in the absence of any added liquid, the outcome was the gradual disappearance of reflections of the two components and apparent amorphisation. A similar experiment, but now with the addition of $50 \mu \mathrm{L}$ of acetonitrile showed that within 10 seconds of milling, reflections associated with a triclinic (cbz)(sac) cocrystal emerged. The reaction was complete within 4 minutes. Such rapidity was to be compared with other solid-solid grinding systems (e.g. the reaction of $\mathrm{ZnO}$ with imidazoles) where reaction timescales were much longer. Similar in situ studies were conducted for suberic acid and nicotinamide demonstrating that formation of a $2: 1$ cocrystal during grinding proceeds via a $1: 1$ cocrystal intermediate (see Fig. 19). Friščić and his colleagues have also used in situ methods, based on the changes in fluorescence ${ }^{122}$ accompanying cocrystallisation, to monitor directly events within the grinding jar.

\section{Concluding remarks}

In the case of pharmaceutical solids, recent work using atomic force microscopy (AFM), terahertz spectroscopy and transmission electron microscopy (TEM) suggests that these techniques will be important for characterising mechanically treated samples and understanding changes which occur during such processing. For example, there are particle-particle effects - especially important during compression in a tablet containing various components. In the case of aspirin (acetylsalicylic acid) and dicalcium phosphate, when the excipient was attached to the tip of the AFM cantilever and different pressures and contact times under various humidity conditions there was evidence for enhanced reactivity induced by surface contact with excipient. ${ }^{91}$ Terahertz spectroscopy has emerged as a sensitive method of monitoring changes in the solid form during mechanical activation, ${ }^{\mathbf{5 6 , 1 5 6}}$ whereas TEM has been shown to be a powerful technique for characterising the size and shape of particulates generated mechanochemically, as well as determining their crystal form (see Fig. 20). TEM can also be used to identify defects in pharmaceutical crystals (see Fig. 21), and will enable a greater understanding of how defects introduced into crystals during mechanical processing influence material properties - for example a link between defects in theophylline crystals and crystal fracture has been established. ${ }^{160}$ 


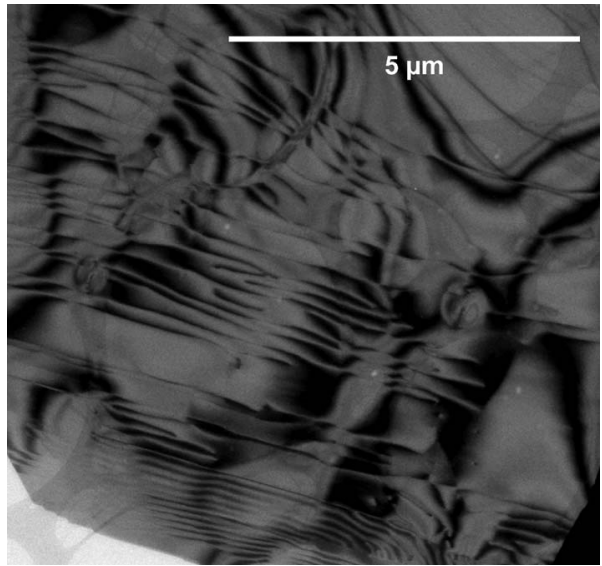

Fig. 21 Extensive network of dislocations in a sample of theophylline as revealed by transmission electron microscopy. In general, such dislocations can result from the mechanical treatment of crystals.

Mechanochemistry, as mentioned at the outset, provides many opportunities for developing environmentally-friendly processes (especially the avoidance of large volumes of solvent). It also provides routes to materials not readily obtained by other methods. It has a long history and no doubt will continue to demonstrate useful applications whilst at the same time generate considerable activity in rationalising the mechanistic aspects behind the many types of transformations observed.

\section{References}

1 L. Takacs, The mechanochemical reduction of $\mathrm{AgCl}$ with metals revisiting an experiment of M. Faraday, J. Therm. Anal. Calorim., 2007, 90, 81-84.

2 L. M. Takacs, Carey Lea, the father of mechanochemistry, Bull. Hist. Chem., 2003, 28, 26-34.

$3 \mathrm{~V}$. V. Boldyrev, Mechanochemistry and mechanical activation of solids, Russ. Chem. Rev., 2006, 75, 177-189.

4 P. Baláž, Mechanochemistry in Nanoscience and Minerals Engineering, SpringerVerlag, Berlin, Germany, 2008.

5 L. Takacs, The historical development of mechanochemistry, Chem. Soc. Rev., 2013, 42, 7649-7659.

6 S. L. James, C. J. Adams, C. Bolm, D. Braga, P. Collier, T. Friščić, F. Grepioni, K. D. M. Harris, G. Hyett, W. Jones, et al., Mechanochemistry: opportunities for new and cleaner synthesis, Chem. Soc. Rev., 2012, 41, 413-447.

7 A. D. McNaught and A. Wilkinson, IUPAC Compendium of Chemical Terminology, Blackwell Scientific Publications, Oxford, 1997.

8 G. Kaupp, Mechanochemistry: the varied applications of mechanical bondbreaking, CrystEngComm, 2009, 11, 388-403.

9 V. V. Boldyrev, Mechanochemistry and sonochemistry, Ultrason. Sonochem., 1995, 2, S143-S145.

10 G. Cravotto, E. C. Gaudino and P. Cintas, On the mechanochemical activation by ultrasound, Chem. Soc. Rev., 2013, 42, 7521-7534. 
11 M. Descamps, J. F. Willart, E. Dudognon and V. Caron, Transformation of pharmaceutical compounds upon milling and comilling: The role of $T_{\mathrm{g}}, J$. Pharm. Sci., 2007, 96, 1398-1407.

12 R. Hüttenrauch, S. Fricke and P. Zielke, Mechanical activation of pharmaceutical systems, Pharm. Res., 1985, 02, 302-306.

13 H. Li, J. G. Stowell, X. He, K. R. Morris and S. R. Byrn, Investigations on solidsolid phase transformation of 5-methyl-2-[(4-methyl-2-nitrophenyl)amino]-3thiophenecarbonitrile, J. Pharm. Sci., 2007, 96, 1079-1089.

14 M. C. Etter, S. M. Reutzel and C. G. Choo, Self-organization of adenine and thymine in the solid state, J. Am. Chem. Soc., 1993, 115, 4411-4412.

15 G. W. V. Cave, C. L. Raston and J. L. Scott, Recent advances in solventless organic reactions: towards benign synthesis with remarkable versatility, Chem. Commun., 2001, 2159-2169.

16 A. S. Cannon and J. C. Warner, Noncovalent derivatization: green chemistry applications of crystal engineering, Cryst. Growth Des., 2002, 2, 255-257.

17 K. Ralphs, C. Hardacre and S. L. James, Application of heterogeneous catalysts prepared by mechanochemical synthesis, Chem. Soc. Rev., 2013, 42, 7701-7718.

18 F. K. Urakaev and V. V. Boldyrev, Theoretical estimation of conditions for the preparation of nanoscale systems in mechanochemical reactors, Russ. J. Phys. Chem., 2005, 79, 563-572.

19 V. K. Smolyakov, O. V. Lapshin and V. V. Boldyrev, Mechanochemical synthesis of nanosize products in heterogeneous systems: macroscopic kinetics, Int. J. Self-Propag. High-Temp. Synth., 2008, 17, 20-29.

20 P. Baláž, M. Achimovičová, M. Baláž, P. Billik, Z. Cherkezova-Zheleva, J. M. Criado, F. Delogu, E. Dutková, E. Gaffet, F. J. Gotor, et al., Hallmarks of mechanochemistry: from nanoparticles to technology, Chem. Soc. Rev., 2013, 42, 7571-7637.

21 M. C. Etter, G. M. Frankenbach and J. Bernstein, Solid-state nucleophilic aromatic substitution reaction of a carboxylic acid cocrystal, Tetrahedron Lett., 1989, 30, 3617-3620.

22 M. A. Mikhailenko, T. P. Shakhtshneider and V. V. Boldyrev, On the mechanism of mechanochemical synthesis of phthalylsulphathiazole, $J$. Mater. Sci., 2004, 39, 5435-5439.

23 R. Trotzki, M. M. Hoffmann and B. Ondruschka, Studies on the solvent-free and waste-free Knoevenagel condensation, Green Chem., 2008, 10, 767-772.

24 A. Bruckmann, A. Krebs and C. Bolm, Organocatalytic reactions: effects of ball milling, microwave and ultrasound irradiation, Green Chem., 2008, 10, 1131-1141.

25 V. Štrukil, M. D. Igrc, L. Fábián, M. Eckert-Maksic, S. L. Childs, D. G. Reid, M. J. Duer, I. Halasz, C. Mottillo and T. Friščić, A model for a solvent-free synthetic organic research laboratory: click-mechanosynthesis and structural characterization of thioureas without bulk solvents, Green Chem., 2012, 14, 2462-2473.

26 J. Stojaković, B. S. Farris and L. R. MacGillivray, Vortex grinding for mechanochemistry: application for automated supramolecular catalysis and preparation of a metal-organic framework, Chem. Commun., 2012, 48, 7958-7960.

27 G.-W. Wang, Mechanochemical organic synthesis, Chem. Soc. Rev., 2013, 42, 7668-7700. 
28 T. Friščić, Supramolecular concepts and new techniques in mechanochemistry: cocrystals, cages, rotaxanes, open metal-organic frameworks, Chem. Soc. Rev., 2012, 41, 3493-3510.

29 V. Šepelák, A. Düvel, M. Wilkening, K.-D. Becker and P. Heitjans, Mechanochemical reactions and syntheses of oxides, Chem. Soc. Rev., 2013, 42, 7507-7520.

30 S. M. Hick, C. Griebel, D. T. Restrepo, J. H. Truitt, E. J. Buker, C. Bylda and R. G. Blair, Mechanocatalysis for biomass-derived chemicals and fuels, Green Chem., 2010, 12, 468-474.

31 T. Kleine, J. Buendia and C. Bolm, Mechanochemical degradation of lignin and wood by solvent-free grinding in a reactive medium, Green Chem., 2013, 15, 160-166.

32 D. Braga, D. D'Addario, L. Maini, M. Polito, S. Giaffreda, K. Rubini, F. Grepioni. Applications of Crystal Engineering Strategies in Solvent-free Reactions: Toward a Supramolecular Green Chemistry, in Frontiers in Crystal Engineering, ed. E. R. T. Tiekink and J. J. Vittal, John Wiley \& Sons, Ltd, Chichester, UK, 2006.

33 A. M. Belenguer, T. Friščić, G. M. Day and J. K. M. Sanders, Solid-state dynamic combinatorial chemistry: reversibility and thermodynamic product selection in covalent mechanosynthesis, Chem. Sci., 2011, 2, 696-700.

34 A. Delori, T. Friščić and W. Jones, The role of mechanochemistry and supramolecular design in the development of pharmaceutical materials, CrystEngComm, 2012, 14, 2350-2362.

35 C. F. Burmeister and A. Kwade, Process engineering with planetary ball mills, Chem. Soc. Rev., 2013, 42, 7660-7667.

36 D.-K. Bučar, S. Filip, M. Arhangelskis, G. O. Lloyd and W. Jones, Advantages of mechanochemical cocrystallisation in the solid-state chemistry of pigments: colour-tuned fluorescein cocrystals, CrystEngComm, 2013, 15, 6289-6291.

37 D. Yan, A. Delori, G. O. Lloyd, T. Friščić, G. M. Day, W. Jones, J. Lu, M. Wei, D. G. Evans and X. Duan, A cocrystal strategy to tune the luminescent properties of stilbene-type organic solid-state materials, Angew. Chem., Int. Ed., 2011, 50, 12483-12486.

38 N. G. Shang, P. Papakonstantinou, S. Sharma, G. Lubarsky, M. Li, D. W. McNeill, A. J. Quinn, W. Zhou and R. Blackley, Controllable selective exfoliation of high-quality graphene nanosheets and nanodots by ionic liquid assisted grinding, Chem. Commun., 2012, 48, 1877-1879.

39 S.-E. Zhu, F. Li and G.-W. Wang, Mechanochemistry of fullerenes and related materials, Chem. Soc. Rev., 2013, 42, 7535-7570.

40 N. Blagden, D. J. Berry, A. Parkin, H. Javed, A. Ibrahim, P. T. Gavan, L. L. De Matos and C. C. Seaton, Current directions in co-crystal growth, New J. Chem., 2008, 32, 1659-1672.

41 P. Baláž and E. Dutková, Fine milling in applied mechanochemistry, Miner. Eng., 2009, 22, 681-694.

42 X. Guo, D. Xiang, G. Duan and P. Mou, A review of mechanochemistry applications in waste management, Waste Manage., 2010, 30, 4-10.

43 A. L. Black, J. M. Lenhardt and S. L. Craig, From molecular mechanochemistry to stress-responsive materials, J. Mater. Chem., 2011, 21, 1655-1663. 
44 E. V. Boldyreva, Mechanochemistry of organic solids: where are we now?, VI International Conference on Mechanochemistry and Mechanical Alloying (INCOME 2008), NML Jamshedpur, India, 2011, pp. 17-30.

45 A. Nasser and U. Mingelgrin, Mechanochemistry: A review of surface reactions and environmental applications, Appl. Clay Sci., 2012, 67-68, 141-150.

46 E. Boldyreva, Mechanochemistry of inorganic and organic systems: what is similar, what is different?, Chem. Soc. Rev., 2013, 42, 7719-7738.

47 G. Majano, L. Borchardt, S. Mitchell, V. Valtchev and J. Perez-Ramirez, Rediscovering zeolite mechanochemistry - A pathway beyond current synthesis and modification boundaries, Microporous Mesoporous Mater., 2014, 194, 106-114.

48 V. V. Boldyrev and K. Tkáčová, Mechanochemistry of solids: past, present, and prospects, J. Mater. Synth. Process., 2000, 8, 121-132.

$49 \mathrm{~V}$. V. Boldyrev, Mechanochemical modification and synthesis of drugs, $J$. Mater. Sci., 2004, 39, 5117-5120.

50 F. Toda, K. Tanaka and A. Sekikawa, Host-guest complex formation by a solid-solid reaction, J. Chem. Soc., Chem. Commun., 1987, 279-280.

51 M. D. Hollingsworth, B. D. Santarsiero, H. Oumar-Mahamat and C. J. Nichols, New series of $1: 1$ layered complexes of $\alpha, \omega$-dinitriles and urea, Chem. Mater., 1991, 3, 23-25.

52 T. Friščić and W. Jones, Recent advances in understanding the mechanism of cocrystal formation via grinding, Cryst. Growth Des., 2009, 9, 1621-1637.

53 V. V. Boldyrev, Hydrothermal reactions under mechanochemical action, Powder Technol., 2002, 122, 247-254.

54 A. A. L. Michalchuk, I. A. Tumanov and E. V. Boldyreva, Complexities of mechanochemistry: elucidation of processes occurring in mechanical activators via implementation of a simple organic system, CrystEngComm, 2013, 15, 6403-6412.

55 T. P. Shakhtshneider, Phase transformations and stabilization of metastable states of molecular crystals under mechanical activation, Solid State Ionics, 1997, 101-103, 851-856.

56 K. L. Nguyen, T. Friščić, G. M. Day, L. F. Gladden and W. Jones, Terahertz time-domain spectroscopy and the quantitative monitoring of mechanochemical cocrystal formation, Nat. Mater., 2007, 6, 206-209.

57 C. Medina, D. Daurio, K. Nagapudi and F. Alvarez-Nunez, Manufacture of pharmaceutical co-crystals using twin screw extrusion: a solvent-less and scalable process, J. Pharm. Sci., 2010, 99, 1693-1696.

58 D. Daurio, K. Nagapudi, L. Li, P. Quan and F. Alvarez-Nunez, Application of twin screw extrusion to the manufacture of cocrystals: scale-up of AMG 517-sorbic acid cocrystal production, Faraday Discuss., 2014, DOI: 10.1039/ C3FD00153A.

59 A. V. Trask, J. van de Streek, W. D. S. Motherwell and W. Jones, Achieving polymorphic and S. diversity in cocrystal formation: Importance of solidstate grinding, powder X-ray structure determination, and seeding, Cryst. Growth Des., 2005, 5, 2233-2241.

60 E. Y. Cheung, S. J. Kitchin, K. D. M. Harris, Y. Imai, N. Tajima and R. Kuroda, Direct Structure determination of a multicomponent molecular crystal prepared by a solid-state grinding procedure, J. Am. Chem. Soc., 2003, 125, 14658-14659. 
61 S. Karki, L. Fábián, T. Friščić and W. Jones, Powder X-ray diffraction as an emerging method to structurally characterize organic solids, Org. Lett., 2007, 9, 3133-3136.

62 E. Salager, G. M. Day, R. S. Stein, C. J. Pickard, B. Elena and L. Emsley, Powder crystallography by combined crystal structure prediction and high-resolution 1H solid-state NMR spectroscopy, J. Am. Chem. Soc., 2010, 132, 2564-2566.

63 K. D. M. Harris, Powder diffraction crystallography of molecular solids, Top. Curr. Chem., 2012, 315, 133-178.

64 M. Arhangelskis, G. O. Lloyd and W. Jones, Mechanochemical synthesis of pyrazine:dicarboxylic acid cocrystals and a study of dissociation by quantitative phase analysis, CrystEngComm, 2012, 14, 5203-5208.

65 U. Kolb, T. E. Gorelik, E. Mugnaioli and A. Stewart, Structural characterization of organics using manual and automated electron diffraction, Polym. Rev., 2010, 50, 385-409.

66 M. D. Eddleston, K. E. Hejczyk, E. G. Bithell, G. M. Day and W. Jones, Polymorph identification and crystal structure determination by a combined crystal structure prediction and transmission electron microscopy approach, Chem.-Eur. J., 2013, 19, 7874-7882.

67 M. D. Eddleston, K. E. Hejczyk, E. G. Bithell, G. M. Day and W. Jones, Determination of the crystal structure of a new polymorph of theophylline, Chem.-Eur. J., 2013, 19, 7883-7888.

68 Y. Qiu, Y. Chen and G. G. Z. Zhang, Developing solid oral dosage forms: Pharmaceutical theory and practise, Academic Press, USA, 2009, p. 943.

69 N. S. Trasi and S. R. Byrn, Mechanically induced amorphization of drugs: A study of the thermal behavior of cryomilled compounds, AAPS PharmSciTech, 2012, 13, 772-784.

70 G. Bruni, V. Berbenni, F. Sartor, C. Milanese, A. Girella, D. Franchi and A. Marini, Quantification methods of amorphous/crystalline fractions in high-energy ball milled pharmaceutical products, J. Therm. Anal. Calorim., 2012, 108, 235-241.

71 S. Desprez and M. Descamps, Transformations of glassy indomethacin induced by ball-milling, J. Non-Cryst. Solids, 2006, 352, 4480-4485.

72 J. F. Willart, N. Descamps, V. Caron, F. Capet, F. Danede and M. Descamps, Formation of lactose-mannitol molecular alloys by solid state vitrification, Solid State Commun., 2006, 138, 194-199.

73 V. Caron, J. F. Willart, F. Danede and M. Descamps, The implication of the glass transition in the formation of trehalose/mannitol molecular alloys by ball milling, Solid State Commun., 2007, 144, 288-292.

74 B. C. Hancock and M. Parks, What is the true solubility advantage for amorphous pharmaceuticals?, Pharm. Res., 2000, 17, 397-404.

75 S. B. Murdande, M. J. Pikal, R. M. Shanker and R. H. Bogner, Solubility advantage of amorphous pharmaceuticals: I. A thermodynamic analysis, $J$. Pharm. Sci., 2010, 99, 1254-1264.

76 A. Newman, G. Knipp and G. Zografi, Assessing the performance of amorphous solid dispersions, J. Pharm. Sci., 2012, 101, 1355-1377.

77 M. Pudipeddi and A. T. M. Serajuddin, Trends in solubility of polymorphs, J. Pharm. Sci., 2005, 94, 929-939. 
78 S.-Y. Lin, W.-T. Cheng and S.-L. Wang, Thermodynamic and kinetic characterization of polymorphic transformation of famotidine during grinding, Int. J. Pharm., 2006, 318, 86-91.

79 P. L. D. Wildfong, K. R. Morris, C. A. Anderson and S. M. Short, Demonstration of a shear-based solid-state phase transformation in a small molecular organic system: chlorpropamide, J. Pharm. Sci., 2007, 96, 1100-1113.

80 A. V. Trask, N. Shan, W. D. S. Motherwell, W. Jones, S. Feng, R. B. H. Tan and K. J. Carpenter, Selective polymorph transformation via solvent-drop grinding, Chem. Commun., 2005, 880-882.

$81 \mathrm{~N}$. Madusanka, Solid state transformations in single-component and multicomponent pharmaceutical crystals, M.Phil thesis, University of Cambridge, UK, 2012.

82 I. Halasz, Single-crystal-to-single-crystal reactivity: Gray, rather than black or white, Cryst. Growth Des., 2010, 10, 2817-2823.

83 H. G. Brittain, Effects of mechanical processing on phase composition, $J$. Pharm. Sci., 2002, 91, 1573-1580.

84 E. V. Boldyreva, V. Dmitriev and B. C. Hancock, Effect of pressure up to 5.5 GPa on dry powder samples of chlorpropamide form-A, Int. J. Pharm., 2006, 327, 51-57.

85 I. D. H. Oswald, I. Chataigner, S. Elphick, F. P. A. Fabbiani, A. R. Lennie, J. Maddaluno, W. G. Marshall, T. J. Prior, C. R. Pulham and R. I. Smith, Putting pressure on elusive polymorphs and solvates, CrystEngComm, 2009, 11, 359-366.

86 M. D. Moore, A. M. Steinbach, I. S. Buckner and P. L. D. Wildfong, A structural investigation into the compaction behavior of pharmaceutical composites using powder X-ray diffraction and total scattering analysis, Pharm. Res., 2009, 26, 2429-2437.

87 I. S. Buckner, R. A. Friedman and D. E. Wurster, Using compression calorimetry to characterize powder compaction behavior of pharmaceutical materials, J. Pharm. Sci., 2010, 99, 861-870.

88 V. Mazel, C. Delplace, V. Busignies, V. Faivre, P. Tchoreloff and N. Yagoubi, Polymorphic transformation of anhydrous caffeine under compression and grinding: a re-evaluation, Drug Dev. Ind. Pharm., 2011, 37, 832-840.

89 R. Roopwani and I. S. Buckner, Understanding deformation mechanisms during powder compaction using principal component analysis of compression data, Int. J. Pharm., 2011, 418, 227-234.

90 N. P. A. Christensen, C. Cornett and J. Rantanen, Role of excipients on solidstate properties of piroxicam during processing, J. Pharm. Sci., 2012, 101, 1202-1211.

91 A. M. Cassidy, C. E. Gardner, T. Auffret, B. Aldous and W. Jones, Decoupling the effects of surface chemistry and humidity on solid-state hydrolysis of aspirin in the presence of dicalcium phosphate dihydrate, J. Pharm. Sci., 2012, 101, 1496-1507.

92 D. Braga and F. Grepioni, Solventless reactions: Reactions between or within molecular crystals, Angew. Chem., Int. Ed., 2004, 43, 4002-4011.

93 A. V. Trask and W. Jones, Crystal engineering of organic cocrystals by the solid-state grinding approach, Top. Curr. Chem., 2005, 254, 41-70.

94 D. Braga, L. Maini and F. Grepioni, Mechanochemical preparation of cocrystals, Chem. Soc. Rev., 2013, 42, 7638-7648. 
95 F. Wöhler, Untersuchungen über das Chinon, Justus Liebigs Ann. Chem., 1844, 51, 145-163.

96 A. O. Patil, D. Y. Curtin and I. C. Paul, Solid-state formation of quinhydrones from their components. Use of solid-solid reactions to prepare compounds not accessible from solution, J. Am. Chem. Soc., 1984, 106, 348-353.

97 V. R. Pedireddi, W. Jones, A. P. Chorlton and R. Docherty, Creation of crystalline supramolecular arrays: a comparison of co-crystal formation from solution and by solid-state grinding, Chem. Commun., 1996, 987-988.

98 R. Kuroda, Y. Imai and N. Tajima, Generation of a co-crystal phasewith novel coloristic properties via solid state grinding procedures, Chem. Commun., 2002, 2848-2849.

99 N. Blagden, M. de Matas, P. T. Gavan and P. York, Crystal engineering of active pharmaceutical ingredients to improve solubility and dissolution rates, Adv. Drug Delivery Rev., 2007, 59, 617-630.

100 S. J. Bethune, N. Schultheiss and J.-O. Henck, Improving the poor aqueous solubility of nutraceutical compound pterostilbene through cocrystal formation, Cryst. Growth Des., 2011, 11, 2817-2823.

101 D. Braga, F. Grepioni, L. Maini, S. Prosperi, R. Gobetto and M. R. Chierotti, From unexpected reactions to a new family of ionic co-crystals: the case of barbituric acid with alkali bromides and cesium iodide, Chem. Commun., 2010, 46, 7715-7717.

102 D. Braga, F. Grepioni, G. I. Lampronti, L. Maini and A. Turrina, Ionic cocrystals of organic molecules with metal halides: A new prospect in the solid formulation of active pharmaceutical ingredients, Cryst. Growth Des., 2011, 11, 5621-5627.

103 O. Almarsson and M. J. Zaworotko, Crystal engineering of the composition of pharmaceutical phases. Do pharmaceutical co-crystals represent a new path to improved medicines?, Chem. Commun., 2004, 1889-1896.

104 G. P. Stahly, Diversity in single- and multiple-component crystals. The search for and prevalence of polymorphs and cocrystals, Cryst. Growth Des., 2007, 7, 1007-1026.

105 N. Shan and M. J. Zaworotko, The role of cocrystals in pharmaceutical science, Drug Discovery Today, 2008, 13, 440-446.

106 N. A. Meanwell, The emerging utility of co-crystals in drug discovery and development, Annu. Rep. Med. Chem., 2008, 43, 373-404.

107 G. P. Stahly, A Survey of Cocrystals Reported Prior to 2000, Cryst. Growth Des., 2009, 9, 4212-4229.

108 T. Friščić and W. Jones, Benefits of cocrystallization in pharmaceutical materials science: an update, J. Pharm. Pharmacol., 2010, 62, 1547-1559.

109 N. Qiao, M. Li, W. Schlindwein, N. Malek, A. Davies and G. Trappitt, Pharmaceutical cocrystals: An overview, Int. J. Pharm., 2011, 419, 1-11.

110 H. G. Brittain, Pharmaceutical cocrystals: The coming wave of new drug substances, J. Pharm. Sci., 2013, 102, 311-317.

111 R. Thakuria, A. Delori, W. Jones, M. P. Lipert, L. Roy and N. RodríguezHornedo, Pharmaceutical cocrystals and poorly soluble drugs, Int. J. Pharm., 2013, 453, 101-125.

$112 \mathrm{~J}$. W. Steed, The role of co-crystals in pharmaceutical design, Trends Pharmacol. Sci., 2013, 34, 185-193. 
113 A. V. Trask, W. D. S. Motherwell and W. Jones, Pharmaceutical cocrystallization: Engineering a remedy for caffeine hydration, Cryst. Growth Des., 2005, 5, 1013-1021.

114 A. V. Trask, W. D. S. Motherwell and W. Jones, Physical stability enhancement of theophylline via cocrystallization, Int. J. Pharm., 2006, 320, 114-123.

115 M. D. Eddleston, R. Thakuria, B. J. Aldous and W. Jones, An investigation of the causes of cocrystal dissociation at high humidity, J. Pharm. Sci., 2014, 103, 2859-2864.

116 M. D. Eddleston, N. Madusanka and W. Jones, Cocrystal dissociation in the presence of water: A general approach for identifying stable cocrystal forms, J. Pharm. Sci., 2014, 103, 2865-2870.

117 C. C. Sun and H. Hou, Improving mechanical properties of caffeine and methyl gallate crystals by cocrystallization, Cryst. Growth Des., 2008, 8, 1575-1579.

118 S. Karki, T. Friščić, L. Fábián, P. R. Laity, G. M. Day and W. Jones, Improving mechanical properties of crystalline solids by cocrystal formation: new compressible forms of paracetamol, Adv. Mater., 2009, 21, 3905-3909.

119 M. L. Brader, M. Sukumar, A. H. Pekar, D. S. McClellan, R. E. Chance, D. B. Flora, A. L. Cox, L. Irwin and S. R. Myers, Hybrid insulin cocrystals for controlled release delivery, Nat. Biotechnol., 2002, 20, 800-804.

120 A. V. Trask, An overview of pharmaceutical cocrystals as intellectual property, Mol. Pharmaceutics, 2007, 4, 301-309.

121 S. Aitipamula, R. Banerjee, A. K. Bansal, K. Biradha, M. L. Cheney, A. R. Choudhury, G. R. Desiraju, A. G. Dikundwar, R. Dubey, N. Duggirala, et al., Polymorphs, salts, and cocrystals: What's in a name?, Cryst. Growth Des., 2012, 12, 2147-2152.

122 M. Frenette, G. Cosa and T. Friščić, Characterisation of organic solid forms and real-time in situ monitoring of their transformations using solid-state fluorescence, CrystEngComm, 2013, 15, 5100-5106.

123 K. B. Landenberger and A. J. Matzger, Cocrystal engineering of a prototype energetic material: supramolecular chemistry of 2,4,6-trinitrotoluene, Cryst. Growth Des., 2010, 10, 5341-5347.

124 J. P. Shen, X. H. Duan, Q. P. Luo, Y. Zhou, Q. Bao, Y. J. Ma and C. H. Pei, Preparation and characterization of a novel cocrystal explosive, Cryst. Growth Des., 2011, 11, 1759-1765.

125 M. R. Caira, L. R. Nassimbeni and A. F. Wildervanck, Selective formation of hydrogen bonded cocrystals between a sulfonamide and aromatic carboxylic acids in the solid state, J. Chem. Soc., Perkin Trans. 2, 1995, 2213-2216.

126 L. Fábián, Cambridge Structural Database Analysis of Molecular Complementarity in Cocrystals, Cryst. Growth Des., 2009, 9, 1436-1443.

127 D. Musumeci, C. A. Hunter, R. Prohens, S. Scuderi and J. F. McCabe, Virtual cocrystal screening, Chem. Sci., 2011, 2, 883-890.

128 G. Springuel, B. Norberg, K. Robeyns, J. Wouters and T. Leyssens, Advances in pharmaceutical co-crystal screening: effective co-crystal screening through structural resemblance, Cryst. Growth Des., 2012, 12, 475-484.

129 P. A. Wood, N. Feeder, M. Furlow, P. T. A. Galek, C. R. Groom and E. Pidcock, Knowledge-based approaches to co-crystal design, CrystEngComm, 2014, 16, 5839-5848. 
130 V. André, D. Braga, F. Grepioni and M. T. Duarte, Crystal forms of the antibiotic 4-aminosalicylic acid: solvates and molecular salts with dioxane, morpholine, and piperazine, Cryst. Growth Des., 2009, 9, 5108-5116.

131 S. R. Bysouth, J. A. Bis and D. Igo, Cocrystallization via planetary milling: Enhancing throughput of solid-state screening methods, Int. J. Pharm., 2011, 411, 169-171.

132 H. Abourahma, J. M. Urban, N. Morozowich and B. Chan, Examining the robustness of a theophylline cocrystal during grinding with additives, CrystEngComm, 2012, 14, 6163-6169.

133 E. Gagnière, D. Mangin, F. Puel, A. Rivoire, O. Monnier, E. Garcia and J. P. Klein, Formation of co-crystals: kinetic and thermodynamic aspects, $J$. Cryst. Growth, 2009, 311, 2689-2695.

134 E. Gagnière, D. Mangin, S. Veesler and F. Puel, Co-crystallization in solution and scale-up issues, RSC Drug Discovery Ser., 2012, 16, 188-211.

135 M. D. Eddleston, S. Sivachelvam and W. Jones, Screening for polymorphs of cocrystals: a case study, CrystEngComm, 2013, 15, 175-181.

136 N. Madusanka, M. D. Eddleston, M. Arhangelskis and W. Jones, Polymorphs, hydrates and solvates of a co-crystal of caffeine with anthranilic acid, Acta Crystallogr., Sect. B: Struct. Sci., Cryst.Eng. Mater., 2014, 70, 72-80.

137 M. D. Eddleston, M. Arhangelskis, T. Friščić and W. Jones, Solid state grinding as a tool to aid enantiomeric resolution by cocrystallisation, Chem. Commun., 2012, 48, 11340-11342.

138 D. Braga, F. Grepioni and G. I. Lampronti, Supramolecular metathesis: coformer exchange in co-crystals of pyrazine with $(R, R)-,(S, S)-,(R, S)$ - and $(S, S /$ $R, R)$-tartaric acid, CrystEngComm, 2011, 13, 3122-3124.

139 N. Shan, F. Toda and W. Jones, Mechanochemistry and co-crystal formation: effect of solvent on reaction kinetics, Chem. Commun., 2002, 2372-2373.

140 S. A. Myz, T. P. Shakhtshneider, K. Fucke, A. P. Fedotov, E. V. Boldyreva, V. V. Boldyrev and N. I. Kuleshova, Synthesis of co-crystals of meloxicam with carboxylic acids by grinding, Mendeleev Commun., 2009, 19, 272-274.

141 C. B. Aakeröy, A. B. Grommet and J. Desper, Co-crystal screening of diclofenac, Pharmaceutics, 2011, 3, 601-614.

142 K. Fucke, S. A. Myz, T. P. Shakhtshneider, E. V. Boldyreva and U. J. Griesser, How good are the crystallisation methods for co-crystals? A comparative study of piroxicam, New J. Chem., 2012, 36, 1969-1977.

143 K. Yamamoto, S. Tsutsumi and Y. Ikeda, Establishment of cocrystal cocktail grinding method for rational screening of pharmaceutical cocrystals, Int. J. Pharm., 2012, 437, 162-171.

144 H.-L. Lin, T.-K. Wu and S.-Y. Lin, Screening and characterization of cocrystal formation of metaxalone with short-chain dicarboxylic acids induced by solvent-assisted grinding approach, Thermochim. Acta, 2014, 575, 313-321.

145 R. A. Chiarella, R. J. Davey and M. L. Peterson, Making co-crystals - The utility of ternary phase diagrams, Cryst. Growth Des., 2007, 7, 1223-1226.

146 K. Chadwick, R. Davey, G. Sadiq, W. Cross and R. Pritchard, The utility of a ternary phase diagram in the discovery of new co-crystal forms, CrystEngComm, 2009, 11, 412-414.

147 S. L. Childs, N. Rodríguez-Hornedo, L. S. Reddy, A. Jayasankar, C. Maheshwari, L. McCausland, R. Shipplett and B. C. Stahly, Screening strategies based on solubility and solution composition generate 
pharmaceutically acceptable cocrystals of carbamazepine, CrystEngComm, 2008, 10, 856-864.

148 T. Friščić, S. L. Childs, S. A. A. Rizvi and W. Jones, The role of solvent in mechanochemical and sonochemical cocrystal formation: a solubilitybased approach for predicting cocrystallisation outcome, CrystEngComm, 2009, 11, 418-426.

149 T. Friščić, D. G. Reid, I. Halasz, R. S. Stein, R. E. Dinnebier and M. J. Duer, Ion- and liquid-assisted grinding: improved mechanochemical synthesis of metal-organic frameworks reveals salt inclusion and anion templating, Angew. Chem., Int. Ed., 2010, 49, 712-715.

150 D. Braga and F. Grepioni, Making crystals from crystals: a green route to crystal engineering and polymorphism, Chem. Commun., 2005, 3635-3645.

151 D. Braga, S. L. Giaffreda, F. Grepioni, M. R. Chierotti, R. Gobetto, G. Palladino and M. Polito, Solvent effect in a "solvent free" reaction, CrystEngComm, 2007, 9, 879-881.

152 D.-K. Bučar, G. M. Day, I. Halasz, G. G. Z. Zhang, J. R. G. Sander, D. G. Reid, L. R. MacGillivray, M. J. Duer and W. Jones, The curious case of (caffeine) (benzoic acid): how heteronuclear seeding allowed the formation of an elusive cocrystal, Chem. Sci., 2013, 4, 4417-4425.

153 S. Heiden, L. Troebs, K.-J. Wenzel and F. Emmerling, Mechanochemical synthesis and structural characterisation of a theophylline-benzoic acid cocrystal (1 : 1), CrystEngComm, 2012, 14, 5128-5129.

154 D. Cinčić, T. Friščić and W. Jones, A stepwise mechanism for the mechanochemical synthesis of halogen-bonded cocrystal architectures, $J$. Am. Chem. Soc., 2008, 130, 7524-7525.

155 I. A. Tumanov, A. F. Achkasov, E. V. Boldyreva and V. V. Boldyrev, Following the products of mechanochemical synthesis step by step, CrystEngComm, 2011, 13, 2213-2216.

156 Y. Du, Y. Xia, H. Zhang and Z. Hong, Using terahertz time-domain spectroscopical technique to monitor cocrystal formation between piracetam and 2,5-dihydroxybenzoic acid, Spectrochim. Acta, Part A, 2013, 111, 192-195.

157 I. Halasz, A. Puškarić, S. A. J. Kimber, P. J. Beldon, A. M. Belenguer, F. Adams, V. Honkimäki, R. E. Dinnebier, B. Patel, W. Jones, et al., Real-Time In Situ Powder X-ray diffraction monitoring of mechanochemical synthesis of pharmaceutical cocrystals, Angew. Chem., Int. Ed., 2013, 52, 11538-11541.

158 T. Friščić, I. Halasz, P. J. Beldon, A. M. Belenguer, F. Adams, S. A. J. Kimber, V. Honkimäki and R. E. Dinnebier, Real-time and in situ monitoring of mechanochemical milling reactions, Nat. Chem., 2012, 5, 66-73.

159 S. Karki, T. Friščić and W. Jones, Control and interconversion of cocrystal stoichiometry in grinding: Stepwise mechanism for the formation of a hydrogen-bonded cocrystal, CrystEngComm, 2009, 11, 470-481.

160 M. D. Eddleston, E. G. Bithell and W. Jones, Transmission electron microscopy of pharmaceutical materials, J. Pharm. Sci., 2010, 99, 4072-4083.

161 T. Friščić, R. W. Lancaster, L. Fábián and P. G. Karamertzanis, Tunable recognition of the steroid $\alpha$-face by adjacent $\pi$-electron density, Proc. Natl. Acad. Sci. U. S. A., 2010, 107, 13216-13221. 